\title{
Fluoroscopic Epidural Steroid Injection: Pain Relief in Discogenic Sciatica Versus Lumbar Spinal Stenosis. A Study on Middle Eastern Patients
}

\author{
Todor Shamov ${ }^{1,2}$, Jasem Y. Al-Hashel ${ }^{3}$, Rossen T. Rousseff $3, *$
}

\begin{abstract}
Objective: To compare the effect of epidural steroid injections (ESI) in patients with discogenic sciatica (Sci) versus patients with lumbar canal stenosis (LSS), not controlled by conservative treatment.

Materials and methods: In our study, 80 patients with Sci and 66 with LSS were included. A single ESI (10 mg dexamethasone in 3 cc $0.25 \%$ bupivacaine) was applied under fluoroscopic control: one level above the highest stenotic level, in the posterior epidural space, via interlaminar approach in LSS and at the prolapse level, in the anterior epidural space, via transforaminal route in Sci. Pain intensity was assessed by VAS at baseline and on days 1,15 and 30 after intervention.

Results: The procedure was successful in 78 Sci and 63 LSS patients. Patients with Sci responded significantly better. At one month, pain reduction over $50 \%$ was achieved in $63 \%(52.3-73.7 \%$ at $p=0.95)$ of Sci but only in $35 \%(23.2-46.8 \%)$ of LSS ( $p=0.03)$. Return to preintervention level happened in $47 \%(34.7-59.3 \%)$ of LSS versus $14 \%(6.3-21.7 \%)$ of Sci patients $(p=0.01)$. In 5 patients the procedure failed, without resulting morbidity.

Conclusion: ESI are more effective in patients with Sci than in single level LSS. In multiple level LSS, results are disappointing
\end{abstract}

\section{KEYWORDS}

epidural steroid injections; intervertebral disc disease; lumbar spinal stenosis; low back pain; sciatica; chronic pain; neuropathic pain.

AUTHOR AFFILIATIONS

${ }^{1}$ Armed Forces Hospital "Jaber Al-Ahmad Al-Sabah", Subhan, 46012, Kuwait

2 Department of Neurosurgery, Military Medical Academy, St Georgi Sofijski Str 3, 1606, Sofia, Bulgaria

${ }^{3}$ Department of Neurology, Ibn-Sina Hospital, Sabah Health Area, Safat 13115, Kuwait

* Corresponding author: Department of Neurology, Ibn Sin Hospital, post box 25427, Sabah Health Area, Safat 13115, Kuwait; e-mail: emg.doctor@hotmail.com

Received: 27 February 2020

Accepted: 2 June 2020

Published online: 10 August 2020

Acta Medica (Hradec Králové) 2020; 63(2): 73-78

https://doi.org/10.14712/18059694.2020.20

(c) 2020 The Authors. This is an open-access article distributed under the terms of the Creative Commons Attribution License (http://creativecommons.org/licenses/by/4.0), which permits unrestricted use, distribution, and reproduction in any medium, provided the original author and source are credited. 


\section{INTRODUCTION}

Vertebrogenic low back pain (LBP) and lower extremity pain is very common and a high socioeconomic burden (1). About $15 \%$ of patients develop chronic LBP that persists throughout life (2). Surgically treated patients develop chronic LBP and/or neuropathic pain ("failed back surgery syndrome") in at least $10 \%$ of cases with discogenic sciatica and in up to $40 \%$ of LSS cases (3).

Early control of vertebrogenic pain may prevent the development of chronic pain and the associated negative outcomes (analgesic abuse/dependence, loss of employment, psychosocial problems etc.) $(2,4)$. It enables early physiotherapy/rehabilitation that improves non-surgical treatment results (5). However, pain control is not always possible with non-invasive means only (6).

Epidural steroid injection (ESI) is a minimally invasive procedure that introduces the medication (often combined with local anesthetic) close to the pathology site, presumably enhancing its local action while minimizing the systemic effects (7). Numerous studies recommend ESI in low back and radicular pain, but others dispute their utility (8-10).

We compare the short-term efficacy of epidural steroid and anesthetic injection for pain relief in Sci and LSS patients, not controlled by conservative therapy alone. We involved Middle Eastern patients only as there are observations of reduced pain tolerance in this population compared with other groups $(11,12)$.

\section{MATERIALS AND METHODS}

\section{STUDY POPULATION}

This prospective case-control study involves 80 patients with discogenic sciatica (Sci) and 66 patients with lumbar spinal stenosis (LSS), recruited at a tertiary Spinal Clinic. The study was approved by the institutional ethics committee and required informed consent from the partic-

Tab. 1 Demographic and clinical patient characteristics.

\begin{tabular}{|l|l|l|}
\hline $\begin{array}{l}\text { Patient } \\
\text { characteristics }\end{array}$ & $\begin{array}{l}\text { Lumbar spinal } \\
\text { stenosis }(\mathrm{n}=66)\end{array}$ & $\begin{array}{l}\text { Discogenic sciatica } \\
(\mathrm{n}=80)\end{array}$ \\
\hline Age (median) & $58(38-76)$ & $52(29-73)$ \\
\hline Sex* & Male 45, female 18 & Male 48, female 30 \\
\hline $\begin{array}{l}\text { Median duration } \\
\text { of the present } \\
\text { complaints (days) }\end{array}$ & $65(42-90)$ & $48(42-60)$ \\
\hline Level of involvement & $\begin{array}{l}\text { Single - 25 } \\
(18 \text { L4/5, 7 L5/S1) }\end{array}$ & $\begin{array}{l}\text { Monoradicular L5 - 22 } \\
\text { Monoradicular S1 - 25 } \\
\text { Biradicular ipsilateral } \\
\text { (L5 and S1) - 18 } \\
\text { Biradicular } \\
\text { contralateral - 10 } \\
\text { Polyradicular - 5 } \\
\text { Three levels - 19 } 19\end{array}$ \\
\hline Sensory deficit & 23 & 33 \\
\hline
\end{tabular}

Notes: significant differences are marked with asterisk (chi-square test for categorical values, Mann-Whitney test for parametric values with non-standard distribution. ipants, in accordance with the Helsinki Declaration. The diagnosis was established by clinical examination and MRI obtained within the 3 months before intervention. Included were patients with low back pain and radicular pain who did not achieve satisfactory pain control and functional improvement after 6 weeks of medical treatment and physiotherapy, as this length of time is considered a transition point from acute to subacute pain stages (13).

Excluded were: 1 . Cases of disc prolapse with extruded disc sequester within the spinal canal (who were offered surgical treatment). 2. Patients who had already undergone operative treatment or epidural injection. 3. Patients with motor deficit (they were offered surgical treatment). 4. Patients with absolute contraindications for corticosteroid treatment (peptic ulcer, uncontrolled hypertension, uncontrolled diabetes, etc.), hypersensitivity to local anesthetics or contrast.

The demographic and clinical features of the two groups are summarized in Table 1.

The clinical assessment and the invasive procedures in this study were personally performed by the authors.

\section{PAIN INTENSITY ASSESSMENT}

Pain was quantified using the visual analogue scale (VAS) (14) at baseline (the day of the procedure) and one, 15 and 30 days thereafter. Non-steroid analgesics were withheld 3 days before ESI and during the observation period.

\section{EPIDURAL INJECTION}

The procedure was performed in the operating theatre. The patient was positioned prone on a radiolucent table, with intravenous catheter inserted and monitoring of the ECG and the blood pressure. The level of the injection and the approach was determined according to nosology (see below). We first infiltrated the subcutaneous tissues at the injection site with $1 \mathrm{ml}$ 1\% lidocaine solution. The epidural space was reached using an $80 \mathrm{~mm}, 18 \mathrm{G}$ spinal cannula (Spinocan, Braun $^{\mathrm{TM}}$ ). Epidurography was first performed by injecting $1 \mathrm{ml}$ iohexol $300 \mathrm{mg} / \mathrm{ml}$ into the epidural space. After fluorographic verification of the needle position, $3 \mathrm{ml}$ $0.25 \%$ bupivacaine and $10 \mathrm{mg}$ dexamethasone was applied.

Injection in the posterior epidural space via the inerlaminar approach was done 1) one level above the highest level of stenosis in all LSS patients and 2) at the level of the disc lesion in 10 Sci patients, who had root symptoms in 2 contralateral dermatomes. We applied the following technique. The level of injection is determined under X-ray guidance. The point of skin penetration is $1-1.5 \mathrm{~cm}$ away from the midline, with the needle directed about 30 degrees towards the midline in the axial plane and 15 degrees rostral in the sagittal plane. The tip of the needle is directed towards the interlaminar space under $\mathrm{X}$-ray control. When reaching the ligamentum flavum we used the "loss of resistance" technique, instilling about $5 \mathrm{cc}$ of air. After entering the epidural space, we always performed aspiration to ensure the needle is not situated intrathecally or within a vessel. Then epidurography was carried out (Fig. 1). Finally, the anesthetic/steroid preparation was applied. 

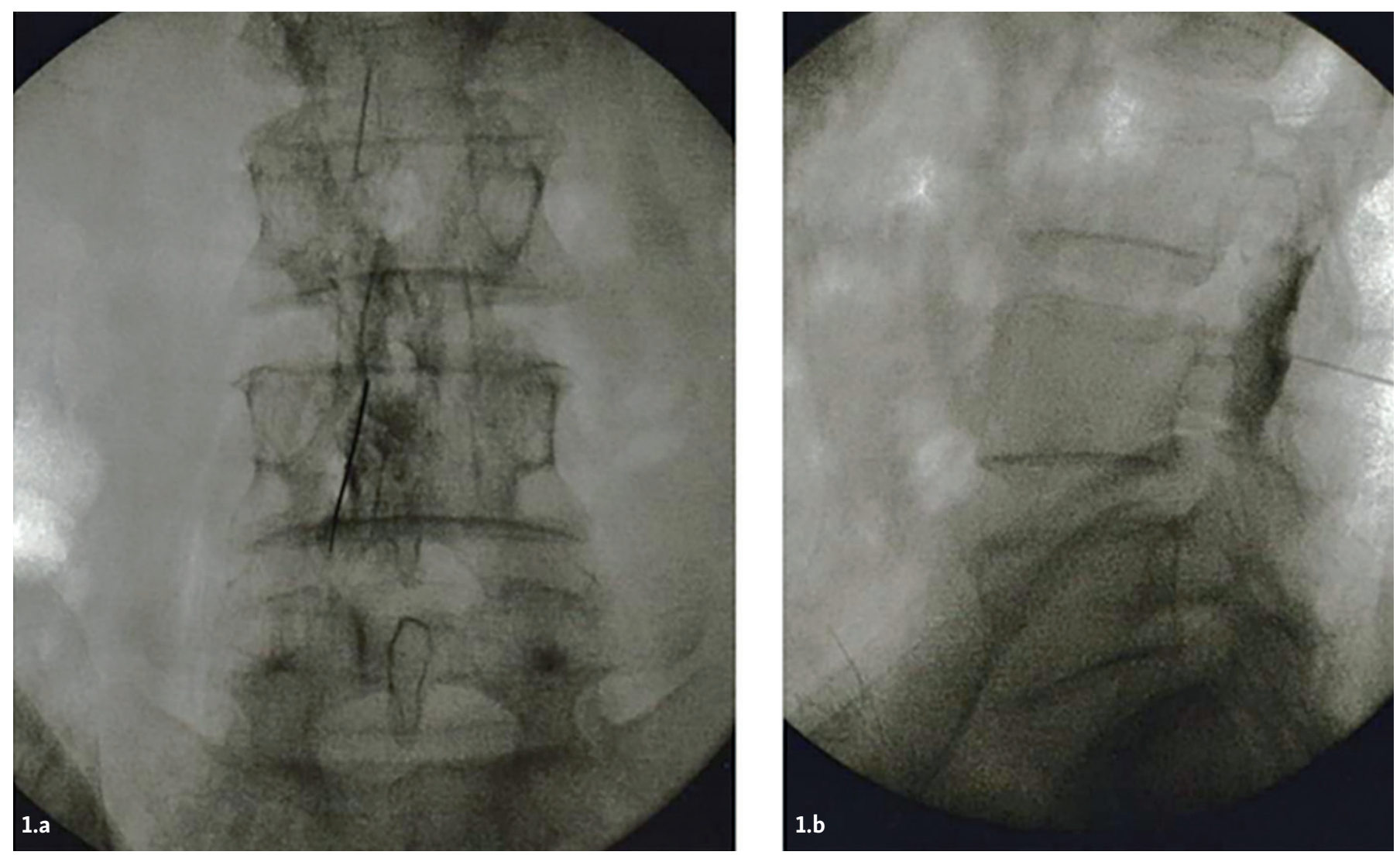

Fig. 1 Epidurography in a patient with LSS at L4-L5 level. 1a) Frontal view, 1b) lateral view. The contrast has spread within the posterior epidural space over at least 2 levels on both sides. A "stop" of the contrast at L4-L5 level is evident.
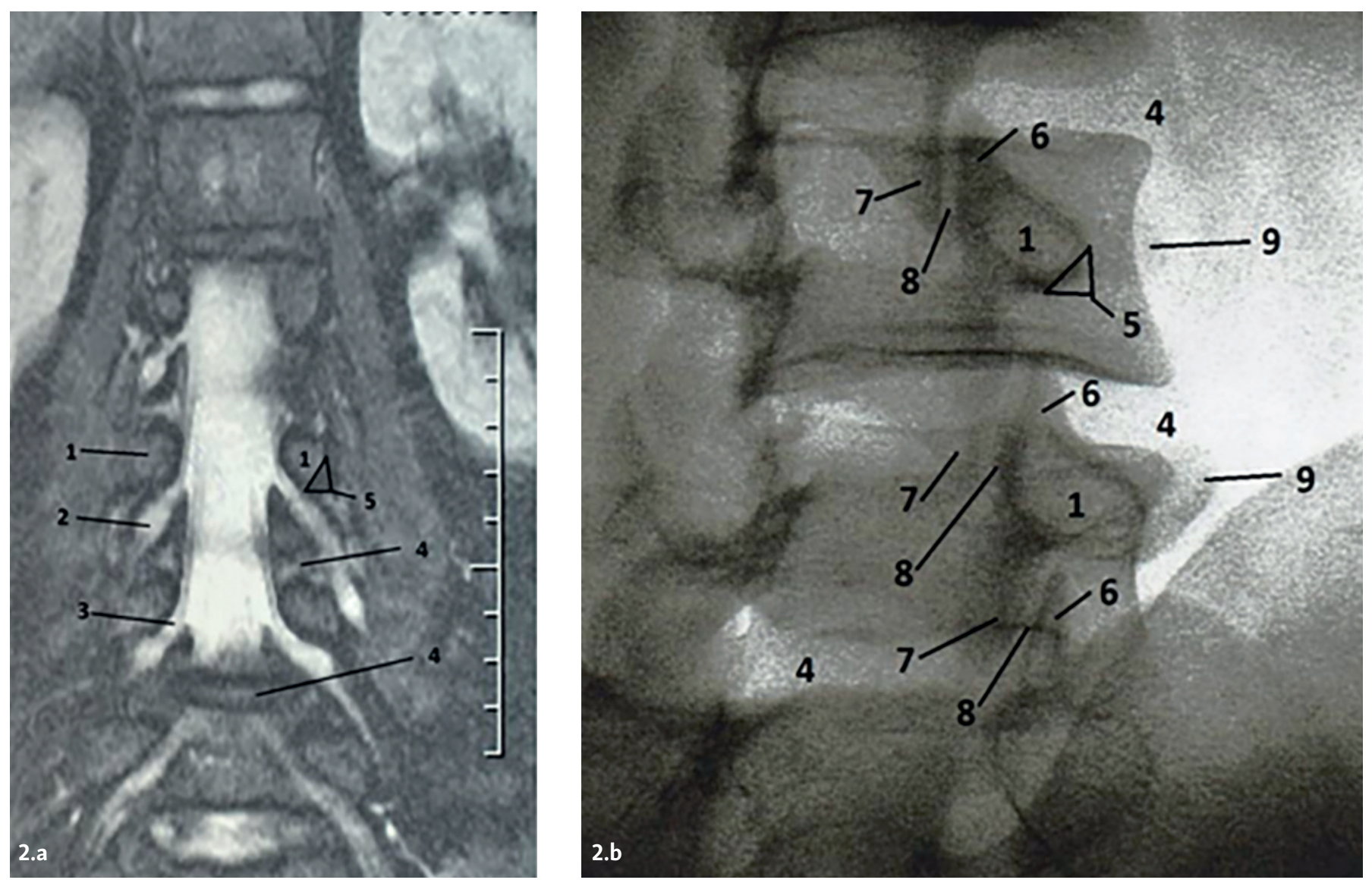

Fig. 2 Anatomic and radiologic detail. 2a - MRI myelography showing the interpositions between the nerve roots and ganglia versus the bone structures and intervertebral discs. $2 b$ - Right oblique "Scotty dog" projection used for transforaminal approach to the anterior epidural space. Numbers indicate: 1 - pedicle of vertebral arch; 2 - dorsal ganglion; 3 - preganglionic nerve root; 4 - intervertebral disc; 5 - safety triangle; 6 - superior articular facet; 7 - inferior articular facet; 8 - facet joint cavity; 9 - transverse process. 
The 70 patients with unilateral Sci received anterior epidural injection via the transforaminal approach. In single disc pathology, it was done at the same level, on the side of the affected root. In multiple disc levels and clinical involvement of 2 or more roots, we approached the rostral disc level on the side of maximal clinical radiculopathy. For visualization with this approach we used oblique left or right projections. The $\mathrm{C}$-arm was inclined to 30 degrees in the axial plane until obtaining the "Scotty Dog" image of the pedicle and adjacent bony structures. To avoid conflict with nerve structures, the needle tip should be directed below the pedicle, into the "safety triangle" defined by the tangential lines of the vertical and horizontal contours of the pedicle, as illustrated in Figure 2.

After reaching the safety triangle, the C-arm is positioned for frontal and lateral projections to verify the proper position of the needle tip. Then epidurography is performed and finally the anesthetic/steroid solution is injected.

All patients were observed for 2 hours after the injection.

The procedure was cancelled in cases of intrathecal or intravasal penetration; these patients were treated conservatively and excluded from further participation.

Statistical methods included descriptive, alternative, variance and non-parametric analysis. Statistical level of significance was accepted at $\mathrm{p}<0.05$.

\section{RESULTS}

In 5 patients $(3.5 \%, 0.2-5.8 \%)$ the procedure was unsuccessful. Three had intrathecal penetration of contrast ( 2 after interlaminar and one after transforaminal approach). In the other two, aspiration yielded blood, indicating a vessel penetration. There was no associated morbidity.

In the remaining 141 patients, the procedure was uneventful. Their total hospital stay (including 2 hours' observation) was 6 hours (3.5-6.8). All completed the scheduled follow-up.

The patients with LSS had significant pain relief. Their reported pain intensity was $6+/-1.8$ VAS score immediately before the intervention, $3.2+/-0.4$ on the day after the injection, $4.3+/-0.6$ two weeks and $5+/-0.4$ at one month respectively. The best results were achieved in the 25 patients with single level stenosis, with $3.8+/-0.9$ VAS score one month after the procedure.

Sci patients improved significantly better. They had initial pain intensity of $7.1+/-1.3$ VAS points, then $3.0+/-0.2$ (day one), $3.6+/-0.4$ (two weeks) and $4.7+/-0.3$ (one month). The 47 patients with single root involvement had a significantly better outcome at one month $(3.9+/-0.7)$.

One-way ANOVA confirmed the significant difference between groups at all comparison points, as illustrated in Figure 4.

The early effects, lasting days to weeks were quite significant in both groups. To better compare the effects of the procedure between LSS and Sci patients at one month we stratified the response at that point of time as good (VAS score decrease with more that $50 \%$ ), satisfactory
(VAS improvement less than 50\%) and poor (return to preoperative values). Results are summarized in Table 2.

The higher effectiveness of the intervention in Sci patients is evident.

\section{DISCUSSION}

ESI produced major short-term improvements, significantly greater in Sci that in LSS patients. After one month, nearly half of the LSS but only about $10 \%$ of Sci patients returned to their pre-intervention condition. The procedure was particularly effective in LSS patients with a single level of stenosis and Sci patients with monoradicular involvement. The percent of failed interventions was very low.

ESI are the most popular interventional technique in low back and lower extremity pain (at least in the United States) and their use continues to increase (15). While their long-term efficacy and cost-effectiveness remain controversial, most experts agree on the short-term pain relief provided, particularly in sciatica $(8-10,15)$. We assessed systematically the efficacy of epidural steroid injections in a Middle Eastern population as significant differences in pain tolerance between Middle Easterners and other cultures have been demonstrated $(11,12)$.

Our study has weaknesses like is the lack of a placebo group (not allowed by the IRB for ethical considerations) that places it into the third class in terms of quality of evidence (16). Another disadvantage is focusing on pain and relying on VAS only. We intended to study functional outcomes using a standard tool (the Oswestry Disability Index) in its Arabic validated translation (17) but it was not well accepted by patients (questions regarding sexual life, hygiene were considered intrusive). As our referrals in a Military Hospital were predominantly male, the sexes proportions in our study cohort are not representative of the incidence of LSS and Sci in the general population.

Despite these shortcomings, we present some significant results.

The efficacy of ESI at one month in our patients was lower than the reported in some studies but similar to or higher than other patient series, originating from very diverse countries and settings and methodologically comparable with our study $(9-11,18-21)$. While a direct comparison across different studies is methodologically not appropriate, we should note that our results tend toward a "median value" and suggest that the differences are not due to lower tolerance to pain in our population but rather to patient selection, to dose of medication used, different study design (blinded, open) and/or other confounding factors.

The significantly higher utility of ESI in Sci compared to LSS in our study confirms some previous reports $(11,22$, 23). It may reflect the different pain mechanisms prevailing in either pathology. In LSS, pain is mostly nociceptive or mixed (nociceptive and neuropathic) (24), determined by mechanical factors. The neuropathic pain component in LSS is considered a consequence of ischemia causing repolarization disturbance of neuronal membranes that 

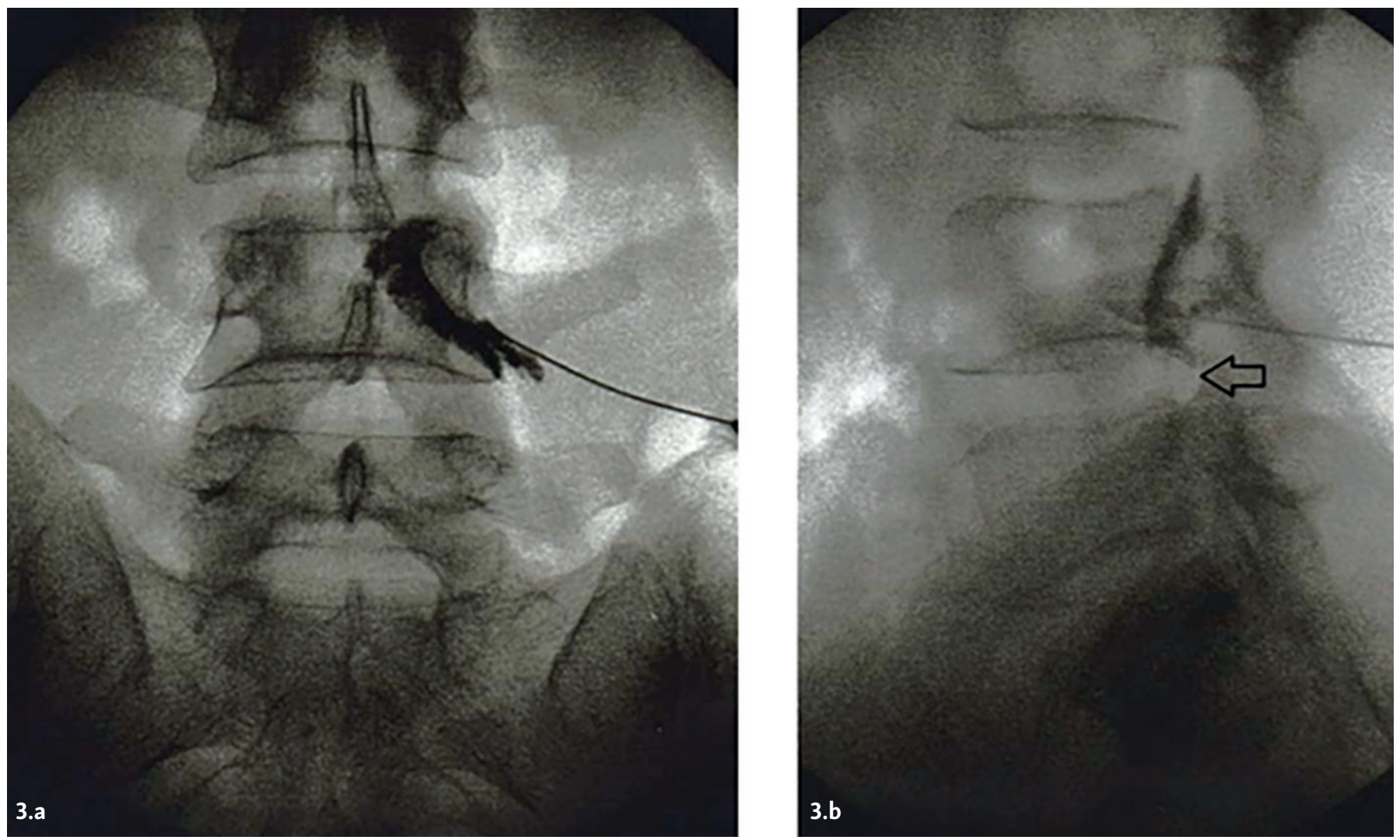

Fig. 3 Epidurography in disc prolapse at L4-L5 level in the frontal (3a) and lateral ( $3 b$ ) projection that visualizes the tip of the needle and the spread of contrast in the anterior epidural space. A "stop" of the contrast by the prolapse (arrow).

manifests clinically as hyperesthesia and neurogenic claudication (24). The membrane-stabilizing effect of steroids with hyperpolarization and inhibition of C-fibers conduction may explain the extended analgesic effect in LSS (25). However, the mechanical and vascular factors involved in LSS would not be corrected by the steroid application.

In contrast, in discogenic radiculopathy the pain is mostly neuropathic and inflammation likely plays a central role (26). Penetration of nucleus pulposus into the superficial layers of annulus fibrosus triggers an immune response, in particular - tumor necrosis factor alpha (TNF- $\alpha$ ) from activated macrophages (27). Inflammation leads to disturbances in microcirculation with alteration of the myelin sheets in the nerve root that produce the clinical manifestations of radiculopathy

\section{VAS}

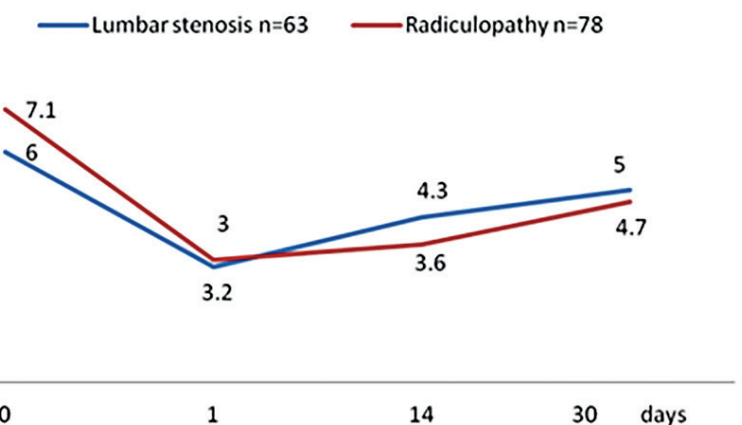

Fig. 4 Mean pain intensity (worst pain irrespective of location) in both groups. $P<0.03$ on day one and $P<0.01$ at all other comparison points (two-way ANOVA).
$(26,27)$. Neuropathic pain may be also related to prostaglandin cascade activation with release of substance $P$ and other mediators in the affected dorsal ganglion (28).

If inflammation has a much greater significance in the pathogenesis of discogenic sciatica, the anti-inflammatory action of steroids would explain their higher efficacy in Sci versus LSS. This is supported indirectly by the effects of epidural application of TNF-a antagonists - etanercept, adalimumab - that alleviate sciatica $(29,30)$. The efficacy of epidural clonidine in neuropathic radicular pain may also partially depend on its anti-cytokine actions (31).

The superior effect of epidural steroid/anesthetic in single-level LSS and in monoradicular Sci is intuitively expected. This finding may be helpful in patient selection.

Complications of ESI, from mild to even fatal have been reported (32), but we didn't observe procedure related

Tab. 2 Epidural anesthetic/steroid injection - results at one month.

\begin{tabular}{|l|l|l|l|}
\hline & $\begin{array}{l}\text { VAS } \\
\text { Improvement } \\
\text { of over 50\% }\end{array}$ & $\begin{array}{l}\text { VAS } \\
\text { improvement } \\
\text { of less than 50\% }\end{array}$ & $\begin{array}{l}\text { Return to } \\
\text { preoperative } \\
\text { levels }\end{array}$ \\
\hline $\begin{array}{l}\text { Patients with } \\
\text { LSS, } \mathrm{n}=63\end{array}$ & $\begin{array}{l}22 \\
(35 \%, 23.2-46.8)\end{array}$ & $\begin{array}{l}11 \\
(18 \%, 8.5-27.5)\end{array}$ & $\begin{array}{l}30 \\
(47 \%, 34.7-59.3)\end{array}$ \\
\hline $\begin{array}{l}\text { Patients with } \\
\text { Sci, } \mathrm{n}=78\end{array}$ & $\begin{array}{l}49 \\
(63 \%, 52.3-73.7)\end{array}$ & $\begin{array}{l}18 \\
(23 \%, 13.7-32.3)\end{array}$ & $\begin{array}{l}11 \\
(14 \%, 6.3-21.7)\end{array}$ \\
\hline
\end{tabular}

Notes: Significant difference in outcomes between LSS and Sci patients is confirmed (Fisher's exact probability test, multiple comparison; $\mathrm{P}=0.0062$ ). 
morbidity neither in the 141 patients with successful injection nor in the minimal percent of cases where we had technical failure.

In conclusion, ESI with fluoroscopic guidance is safe, effective in short term pain relief and may be routinely recommended for patients with Sci and single level LSS, if conservative measures are not sufficient. In multiple level LSS, well-motivated patients should be selected for ESI.

\section{DISCLOSURE}

The authors declare no conflicts of interest related with this article.

\section{REFERENCES}

1. Hoy D, March L, Brooks P, et al. The global burden of low back pain: estimates from the Global Burden of Disease 2010 study. Ann Rheum Dis 2014; 6: 968-74.

2. Mehling WE, Gopisetty V, Bartmess E, et al. The prognosis of acute low back pain in primary care in the US: a 2-year prospective cohort study. Spine 2012; 37: 678-84.

3. Chan CW, Peng P. Failed back surgery syndrome. Pain Med 2011;12: 577-606.

4. Chou R, McCarberg B. Managing acute back pain patients to avoid the transition to chronic pain. Pain Manag 2011; 1: 69-79.

5. Arnold E, La Barrie J, DaSilva L, et al. The impact of timing of physical therapy for acute low back pain on health services utilization: a systematic review. Arch Phys Med Rehabil 2019; 100: 1324-38.

6. Chou R, Deyo R, Friedly J, et al. Noninvasive treatments for low back pain [Internet]. Rockville (MD): Agency for Healthcare Research and Quality (US); 2016 Feb. Available from: https://www.ncbi.nlm.nih .gov/books/NBK350276/ accessed 05.03.2019.

7. McLain RF, Kapural L, Mekhail NA. Epidural steroid therapy for back and leg pain: mechanisms of action and efficacy. Spine J 2005; 5: 191-201.

8. Rivera CE. Lumbar epidural steroid injections. Phys Med Rehabil Clin N Am 2018; 29: 73-92.

9. Pinto RZ, Maher CG, Ferreira ML, et al. Epidural corticosteroid injections in the management of sciatica: a systematic review and meta-analysis. Ann Intern Med 2012: 157: 865-77.

10. Liu K, Liu P, Liu R, Wu X, Cai M. Steroid for epidural injection in spinal stenosis: a systematic review and meta-analysis. Drug Des Devel Ther 2015; 9: 707-16

11. Dawson A, List T. Comparison of pain thresholds and pain tolerance levels between Middle Easterners and Swedes and between genders. J Oral Rehabil 2009; 36: 271-8.

12. Rahavard B, Candido K, Knezevic N. Different pain responses to chronic and acute pain in various ethnic/racial groups. Pain Manag 2017; 7: 427-53.

13. Thienhaus O, Cole B. Classification of pain. in Weiner R. Pain management: A practical guide for clinicians, 6th ed. CRC Press, 2002, pp. 28-30.
14. Huskisson E. Measurement of pain. Lancet 1974; 2: 1127-31.

15. Manchikanti L, Pampati V, Falco FJ, Hirsh JA. Assessment of the growth of epidural injections in the medicare population from 2000 to 2011. Pain Physician 2013; 16: 349-4.

16. Sackett D, Rosenberg W, Gray J, et al. Evidence based medicine: what it is and what it isn't. BMJ 1996; 312(7023): 71-2.

17. Guermazi M, Mezghani M, Ghroubi S, et al. [The Oswestry index for low back pain translated into Arabic and validated in a Arab population]. Annales de readaptation et de medecine physique 2005; 48: $1-10$.

18. Ackerman WE, 3rd, Ahmad M. The efficacy of lumbar epidural steroid injections in patients with lumbar disc herniations. Anesth Analg 2007; 104: 1217-22.

19. Park CH, Lee SH. Correlation between severity of lumbar spinal stenosis and lumbar epidural steroid injection. Pain Med 2014; 15: 556-61.

20. Kamble PC, Sharma A, Singh V, Natraj B, Devani D, Khapane V. Outcome of single level disc prolapse treated with transforaminal steroid versus epidural steroid versus caudal steroids. Eur Spine J 2016; 25 : 217-21.

21. Kawu AA. Epidural steroid injection in patients with lumbosacral radiculopathy in Abuja, Nigeria. J Neurosci Rural Pract 2012; 3: 121-5.

22. Rivest C, Katz JN, Ferrante FM, Jamison R. Effects of epidural steroid injection on pain due to lumbar spinal stenosis or herniated disks: a prospective study. Arthritis Care Res 1998; 11: 291-7.

23. Mobaleghi J, Allahdini F, Nasseri K, et al. Comparing the effects of epidural methylprednisolone acetate injected in patients with pain due to lumbar spinal stenosis or herniated disks: a prospective study. Int J Gen Med 2011; 4: 875-8.

24. Bagley C, MacAllister M, Dosselman L, Moreno J, Aoun S, El Ahmadieh T. Current concepts and recent advances in understanding and managing lumbar spine stenosis. F1000Res. 2019 Jan 31; 8. doi: 10.12688/f1000research.16082.1. Accessed on 05.03.2019.

25. Johansson A, Hao J, Sjolund B. Local corticosteroid application blocks transmission in normal nociceptive C-fibers. Acta Anaesthesiol Scand 1990; 34: 335-8.

26. Mulleman D, Mammou S, Griffoul I, et al. Pathophysiology of disk-related sciatica. I. - Evidence supporting a chemical component. Joint Bone Spine 2006; 73: 151-8.

27. Di Martino A, Merlini L, Faldini C. Autoimmunity in intervertebral disc herniation: from bench to bedside. Expert Opin Ther Targets 2013; 17: 1461-70.

28. Kobayashi S, Kokubo Y, Uchida K, et al. Effect of lumbar nerve root compression on primary sensory neurons and their central branches: changes in the nociceptive neuropeptides substance $\mathrm{P}$ and somatostatin. Spine 2005; 30: 276-82.

29. Cohen SP, Bogduk N, Dragovich A, et al. Randomized, double-blind, placebo-controlled, dose-response, and preclinical safety study of transforaminal epidural etanercept for the treatment of sciatica. Anesthesiology 2009; 110: 1116-26.

30. Genevay S, Finckh A, Zufferey P, et al. Adalimumab in acute sciatica reduces the long-term need for surgery: a 3-year follow-up of a randomised double-blind placebo-controlled trial. Ann Rheum Dis 2012; 71: 560-2.

31. Romero-Sandoval A, Eisenach JC. Perineural clonidine reduces mechanical hypersensitivity and cytokine production in established nerve injury. Anesthesiology 2006: 104: 351-5.

32. Epstein NE. The risks of epidural and transforaminal steroid injections in the spine: Commentary and a comprehensive review of the literature. Surg Neurol Int 2013; 4(Suppl 2): S74-S93. 